\title{
Considerations Towards a Sustainable and Resilient Supply Chain: A Modelling Perspective
}

\author{
Nicoleta S. Tipi(1), and Sara Elgazzar ${ }^{(2)}$
}

(1) The Open University, Department of People and Organisations, Open University Business School, Faculty of Business and Law, UK E-Mail: nicoleta.tipi@open.ac.uk

(2) Arab Academy for Science, Technology and Maritime Transport, College of International Transport and Logistics, Alexandria, Egypt E-Mail: sara.elgazzar@aast.edu

\section{Abstract}

Purpose: The development of models and application of modelling techniques are particularly important in supporting and enhancing our understanding of what happens in the supply chain, in gaining appreciation of what may happen in the future and what will be the most appropriate solution to work with. Research in modelling supply chain systems is however infrequent.

Design/ methodology/ approach: Several theoretical and practical examples reported in the literature capture aspects of modelling and their benefits and limitations, still when approached from the point of view of the supply chain, the issues they managed to report on are however limited. Supply chains analysis are looking to respond to issues linked to effectiveness and efficiency, to sustainability, to resilience, to allow for opportunity for innovation and others.

Findings: This research paper aims to provide an understanding of how modelling supply chains can be approached by evaluating modelling characteristics from the point of view of sustainability and resilience.

Keywords: Sustainability, Supply Chain Management, Resilience, Modelling.

\section{Introduction}

A range of different models and modelling techniques are employed along the supply chain with the scope to bring implementable solutions to particular issues internal or external to an organisation or a group of organisations that are coming together to form a supply chain. Some of these issues may be finding the best location to place a warehouse by employing the well-known facility location model; or calculating the minimum total transportation cost by using an optimisation modelling technique; or determining the minimum

distance travelled between various distribution or collection points by employing a vehicle routing and scheduling algorithm (Tipi, 2021); or identifying the most appropriate safety stock level by considering an inventory control procedure; or may be to understand what may happen in the future with the operation of the chain and many others. There are limited examples of models, however, that capture a collection of issues along the supply chain system and models are rarely integrated to decipher a larger set of issue in the supply chain, or respond to a larger number of objectives set at individual points in the chain. 
It is therefore imperative to understand the extent an optimum solution generated for an individual part of a supply chain can positively influence the overall performance of the entire supply chain. Acar and Atadeniz (2015) noted in their study of a globally dispersed supply chain, that integrating planning and decision marking within a model results in a more effective allocation of resources, better customer service performance and reacts positively when demand uncertainty is high. There is also the argument from Min and Zhou (2002) who indicated that no model could capture all aspects of supply chain processes when considering the broad spectrum of a supply chain. Therefore, one other key question to be asked at this point is to what degree current models are capable of capturing complexity within a supply chain that will generate an improvement in the behaviour of the whole supply chain system.

It is evident that effort needs to focus on developing models that can integrate and capture issues along the supply chain. It is relevant to understand how modelling can be used to support approaches leading to supply chain sustainability; models that integrate the three dimensions of sustainability such as the economic, environmental and social aspect.

Therefore, this paper is set to provide a discussion on these lines and is organised as follows: the next section is aiming to provide a definition of supply chain and refers to complexity issues governing the supply chain system and the type of analysis that can be carried out in a supply chain. Following this, this paper is looking to establish the reason for modelling with the view to set objectives that lead to a sustainable and resilient chain. Characteristics on what is understood under the definition of supply chain sustainability and resiliency will be offered at this point. This discussion leads to the following section on modelling characteristics for sustainable and resilient supply chains.

The paper concludes with attempting to provide an answer to the following question what modelling strategy and characteristics can be approached to achieve sustainable supply chain goals while maintaining its resilience? This is also by looking at what is seen as the future steps is modelling supply chains.

\section{1-Providing a definition of supply chains}

Several definitions have been established when referring to supply chain systems that capture the set of activities that characterises a typical supply chain system. Min and Zhou, (2002, p231) refers to the supply chain as an "integrated system" that aims to "synchronise" a set of inter-related business processes with the scope to: "acquire materials and parts; transform them into finished or semi-finished products; add value to these products; distribute these products to retailers or final consumers; and facilitate information exchange among various business entities". The definition considered here, gives us the understanding of the large number of processes and activities that need to take place when referring to a supply chain system and the complex nature of operations that need to integrate when all these activities are coming together. However, we get a good understanding of what supply chains may comprise of and we see this definition from the point of view of material and information flow to which we should also add orders flow, financial flow and service flow (Tipi, 2021).

Many definitions present in the literature tend to capture the list of activities, systems and operations, the various flows of material, information, services and emphasise the complex nature of a supply chain. When approaching complexity in the supply chain, many authors refer to structural aspects such as: Beamon and Chen (2001) looking at convergent, divergent, conjoined and general networks; Jain and Benyoucef (2008) refers to "long supply chains" and Mentzer et al. (2001) refers to direct, extended and ultimate supply chain. Other complexity issues are captured by Wilding (1998) who introduced the supply chain complexity triangle, which considers elements such as deterministic chaos, parallel interaction and demand amplification. Bozarth et al. (2009) brings forward detail complexity when looking at the number of components that form the system and dynamic complexity that refers to the integration and level of variations that elements forming the system bring in.

The number of organisations forming the supply chain 
at any one time, can increase or decrease due to the nature of the business they conduct, as well as a set of organisations can be part of more than one chain. Therefore, we see the linear structure of a supply chain (formed of suppliers, manufacturers, distributors, retailers) moving to a network structure where a set of organisations could be part of more than one supply chain system. This is known as interlinked supply chains (see Figure 1). The approach of interlinked supply chains has also been observed and discussed in Ivanov and Dolgui (2020) where they refer to the intertwined supply network seen as a system of interconnected supply chains.

It is also relevant to note, and as exemplified in Fig. 1, the system of supply chain does not finish with the forward flow of materials, as this needs to take into consideration the reverse flow as soon as returned or recovered products are coming back into the chain.

To be in a position to start the analysis of a supply chain system some of the considerations that need to be given are as below:

- the boundary of the system under analysis needs to be established

- the nature of the relationships between organisations to be clearly understood

- the objectives of the system to be clearly established, and these to be connected with the objectives set for individual organisations forming part of the chain

- performance measures are being constructed for the selected supply chain system under analysis

- the dynamic nature of the chain is understood before starting the analysis

- the data collected to support the analysis is available and free of errors.

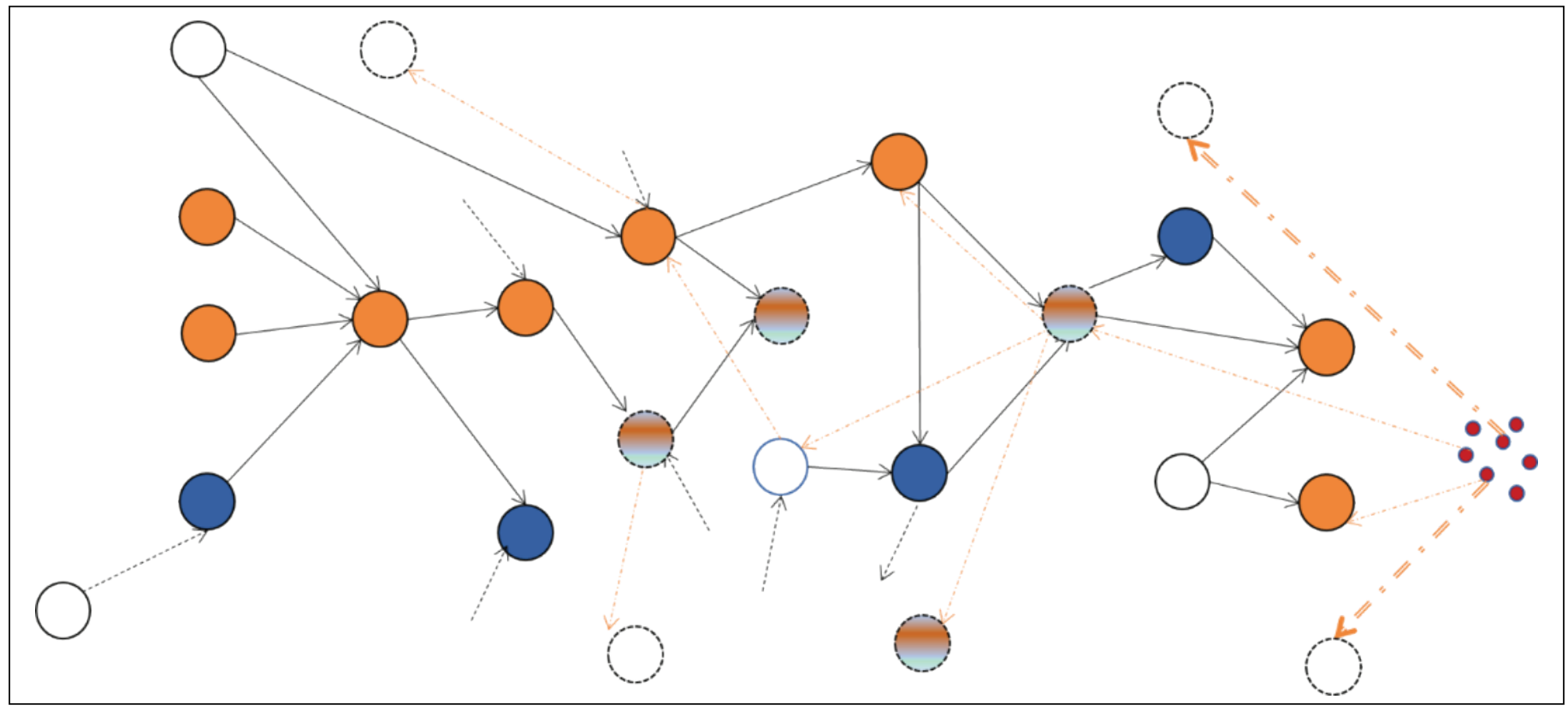

Figure 1 - Interlinked networks of supply chains

\section{2-Considerations for modelling a supply chain}

Pidd (2010, p.10) defines a model as an "extended and explicit representation of parts of reality as seen by people who wish to use that model to understand, to change, to manage and to control that part of reality". For a supply chain, due to its level of complexity, it will be particularly challenging to try to model the entire chain, therefore a section of the chain can be established to represent a part of reality. Still, this is to consider that the system under consideration may be influenced by the external factors that are not yet brought under analysis (Tipi, 2021), therefore the analysis may not be sufficiently detailed, or may not be sufficiently accurate.

One other consideration that needs to be established is the selection of objectives for individual organisations forming the supply chain under analysis, as well as objectives for the entire system. It is considered that individual organisations within a chain have well established objectives that are characterised by 
well determined performance measures. Still, when referring to a supply chain system, there is the issue of understanding which objectives are being set for the system under investigation. Also, it is relevant to enquire who will be responsible to set these objectives. The analyst interested in evaluating an extended chain will set objectives for the analysis they are carrying out, still this may not correspond to the objectives set by other analysts who may also be interested to carry out similar investigations. The objectives set may be to understand if the system is running effectively, is efficient, is lean, agile, is sustainable, is robust, is resilient. There may be situation when an analyst may not have sufficient data or the required infrastructure to be able to set all these objectives, and they may select only a few, however this aspect will also limit the analysis and will provide a restricted view on what is currently happening in the supply chain.

Considerations need to be given to the data available for analysis. Organisations forming part of the chain will have data they are responsible for, known as data internal to an organisation. Still, data is also generated outside an organisation (Tipi, 2021) and this may come in different forms and sizes. It is relevant to understand who owns the data required for analysis, how can this data be accessed, collected and formatted ready for analysis. This data will also need to be saved in a secure place. To be in a position to carry out an extended analysis, data needs to be available for the same set of pre-established variables, for the same time period, collected using the same format, and free of any errors. As there is no direct ownership of data required for an extended chain, and as data needs to be collected, maintained and saved using organisations' internal resources, this poses one of the most challenging aspect in carrying out analysis for a supply chain, data availability.

Setting performance measures within and organisation and along the supply chain is another consideration that needs to be taken when modelling a supply chain. There may be situations when setting a performance measure within an organisation may have a different definition or use a different formula when defining, implementing and using this measure (Tipi, 2021; Tipi, 2009). However, we see an increased attention to develop measures that incorporate additional functions (e.g. responsiveness, reliability, flexibility, assets) within an organisation (ElGazzar et al., 2019) and capture more aspects from a supply chain perspective.

\section{3-Modelling for sustainability and resiliency}

Supply chain are complex system, with many actors being part of the chain with various levels of interaction and decision (from suppliers, to their services, transportation, manufacturers, warehouses, retailers, consumers). Therefore, sustainability in the supply chain is referring to the actions of all the players in the chain who are coming together in an harmonious way, who integrate to deliver products and services that are considered not only from an economic point of view but also from an environmental and social point of view. Sustainability from an environmental perspective is referring to maintain a green agenda, to minimise and reduce harmful impact to the environment; from an economic point of view, is being able to operate over a period of time and bring profit to organisations forming part of the chain; from a social perspective to meet human needs and aspirations, to ensure up to date skills and knowledge, to provide appropriate training and many others.

Aspects such as increased demand volatility and innovation, stricter laws, competition at a supply chain lever, very long supply chains, globalisation, and a push towards competitiveness have all added to the complexity of the supply chain vulnerabilities (Christopher, 2011; Ansari and Kant, 2017; Grant et al., 2017). In the past two decades, academic research on the design and modelling towards a sustainable supply chains have made substantial progress in meeting these needs (Fahimnia et al., 2019; Brandenburg et al., 2014).

Given the environmental cost of the supply chain and the harm this may bring to human health and society in general, research on sustainability has indicated that approaching supply chain analysis from a sustainability perspective could have a positive influence not only on reducing the environmental harm but also benefits can be noted on profitability, performance, and competitiveness (Fahimnia, and Jabbarzadeh, 2016). The sustainable management and actions of an organization encompass not only environmental and social aspects but also their 
integration with economic performance. Therefore, the actions of the sustainable supply chain cover the operational, environmental, and social dimensions of the supply chain not only economically, but also financially (Baliga et al., 2019).

Referring to the most recent global financial crises and the growing frequency of natural and anthropogenetic disasters, Fahimnia, and Jabbarzadeh, (2016) highlight the need for corporations to ensure that they protect themselves from disastrous disturbances. Therefore, to quickly adjust to disorders and disruptions, today's supply chains networks need to be more resilient and agile. In general, these interruptions are handled at a tactical level through more flexibility in the supply chain. Hence, there is a need for management approaches and optimisation strategies to establish resilient and sustainable supply chains (Fahimnia, and Jabbarzadeh, 2016). This raises an important question: When and how is it conceivable for a supply chain to sustain economic expansion, while simultaneously reduce the negative impact on society and environmental by supporting characteristics of resiliency in design.

Resilience is known as the ability of a system, and in our case a supply chain system, to return to operating conditions within an acceptable period of time (Hearnshaw et al, 2013), after being disturbed. In other words, is the ability of the supply chain system to recover after disruptions, and to facilitate the flows in the supply chain, to operate within normal conditions.

Empirical evidence and literature reviews show that sustainability and resilience influence each other, as Negri et al., (2021) noted that the primary objective of supply chain resilience is not to increase efficiency but to promote flexibility and redundancy. Generally, this results in higher costs when the resilience of the supply chain is strengthened. Strategies that might improve supply chain sustainability and resilience at the same time are unclear. While certain practices such as sustainable resource use relate to the growing resilience of the supply chain, these win-win opportunities require further investigation. By reducing stocks, for example, increasing the efficiency and sustainability of organizations might limit their ability to adjust to disruptions in supply. Therefore, within the supply chain it is critical to increase sustainability. Resilience focuses on the design of the network (suppliers and clients) and on sharing of information between network members.

Studies have investigated sustainability and resilience's effects on supply chain and organisational performance. For example, to be environmentally sustainable, the aim is to look at saving the available resources, reducing the amount of damage to the environment, reducing the waste sent into the landfill, where to be resilient in the time of crises, is to look at ensuring that there is access to more resources that will then create a bottleneck in the chain, however, short term there will be the benefit of coping through critical situations. Some studies have lately stated that integrating sustainability into corporate operations might result in enhanced firm performance. Similarly, resilience should be viewed as a source of competitive advantages, instead of simply a tool for risk reduction.

The COVID-19 pandemic has exposed numerous new issues for supply chain and operations management, creating an untapped study area- and as named by (Ivanov, 2020), supply chain viability - that draws on and extends that practically all current fields of supply chain and operations management, and new research streams might arise. The capability of a supply chain to maintain itself and persevere in a changing environment, with the restructuring of structures and re-planning economic performance with long-term effects, is referred to as viability. This is known as the Viable Supply Chain (VSC), combining sustainability and resilience approaches (Ivanov, 2020).

\section{4-Future considerations of supply chain modelling}

While the many advantages of integrated supply chain principles are evident, analytical tools that can take advantage of them are rare. The lack of such instruments may stem from misunderstanding intrinsic to integrated modelling from the supply chain concept and complexity (Min and Zhou, 2002).

Indeed, the main focus of the efforts to shape the supply chains as previously indicated in (Min and Zhou, (2002) was still well-defined issues such as location/allocation, 
inventory control, manufacturing planning, transportation mode selection, and selection by suppliers with commonly accepted value proposals such as cost reduction and profit maximization. These constraints do not signify the disappearance of some old models, such as approaches to mathematical programming techniques but rather the diversity of analytical techniques for analysing supply chains. In 2002, Min and Zhou have indicated some future considerations for modelling the supply chain modelling: The application of conventional mathematical programming (e.g. mixed integer programming) to inter-functional integration should continue to explore multi-echelon, multi-period problems.

New issues in regard to soft concerns, like relationships between supply chain partners and dispute resolution (e.g. buyers and suppliers) should be addressed in future models. They have also indicated that supply chain is a complex network of organisations, which means that future supply chain research will need to cover multi-objective collaborative procurement, manufacturing, and planned assets that take care of total cost/customer service trade offsets. Future research efforts can examine new methods like the Theory of constraints (TOC) to decrease the complexity of the supply chain. Instead of building a huge, stand-alone mathematical model with a broad scale of the supply chain problem, future research should focus on designed model-based decision support systems that employing using communication mechanisms (e.g. the Internet), knowledge finding techniques (e.g. data mining), and visual aids (e.g. GIS). The wave of the future will thus be to develop IT-driven models.

Since 2002, further considerations have been given to the modelling approach in the supply chain. We have research from Brandenburg et al., (2014) where they recommend that outside the inter-organisational aspects that are considered at functional level within the supply chain, analyses on transportation and warehousing are recommended in the future. They have also indicated, that these are to be supported by research that looks into "intermodal transportation that has the option to reduce the greenhouse gas emissions", or work could be focus on vehicle routing problems and the considerations to be given to incorporating driver's working time. It is also noted in their work that environmental risk management offers potential in model-based in the area of sustainable supply chain management, as well as the integration of model-based methods with empirical research that looks into eco-efficiency, environmental aspects as well as the need to incorporate social sustainability research. At that point in time, they have also identified that sophisticating models such as dynamic programming, evolutionary computation, local search methods, were considered only sporadic in the area of sustainable supply chain management research.

In 2015, Brandenburg and Rebs, add that there is a limited number of stochastic approaches that model all dimensions of sustainability with the conclusion that the preferred models are the less complex deterministic models. In their review study, it is concluded that this area of investigation is relatively new and however there are normative and descriptive models considered in sustainable supply chain management research, deterministic approaches are more frequent than stochastic models. Models in this area appear more often on manufacturing and planning processes, however retail and wholesalers' problems appear to be overlooked (Brandenburg and Rebs, 2015). They are indicating that only a minority of models reflect the three dimensions of the triple bottom line. The management of mitigation of sustainability risk can be approached with stochastic optimisation models where some suitable techniques can be fuzzy logic, grey systems theory and rough set theory.

Also, the indication is that sustainable supply chain management models should measure the sustainability performance when all three dimensions are considered such as the environmental, social and economic dimensions.

In 2019, Ivanov et al., highlight as future research in the area of supply chain analytics that there is the move from competition between supply chain to competition between information services and analytics approaches and algorithms. It is mentioned here that success in supply chain competition is more and more dependant on analytics that are coming in combination with optimisation and simulation modelling.

In, 2020, Ivanov is asking questions such as: are the well-established resilience measures still in a position 
to help companies to recover from the pandemic? And are the digital technologies able to help and lessen the effects of severe risks during the globally propagated disruptions, such as the global pandemic. Within this study, Ivanov puts forward the definition of supply chain viability, where it is mentioned that analysis for this type of supply chain could be supported by almost all quantitative and empirical methodologies. Examples are provided on optimisation techniques, simulation models, ecological modelling, Bayesian networks, game theory studies and other hybrid data-driven models in connection with optimisation techniques.

In 2021, Tipi has developed a systematic review of various research in the area of supply chain analytics where a number of very interesting themes have been identified and are put forward as future themes for further investigation in the area of supply chain analytics. Some of these captures not only aspects of big data analytics; digitalisation, digital supply chain; information accuracy, completeness and timeliness; expert systems; but also, resilience and sustainability in the supply chain; self-thinking supply chain; supply chain 4.0 and others.

It can be concluded that there are a number of modelling and analytical efforts in the area of supply chain where further investigations are still expected that are not only complex in their modelling approach, but also capture complex issues that are capable to further highlight what needs to be considered in achieving a sustainable and resilient supply chain.

\section{References}

[1] Acar, Y., \& Atadeniz, S. N. (2015), "Comparison of integrated and local planning approaches for the supply network of a globally-dispersed enterprise", International Journal of Production Economics, Vol. 167, pp. 204-219. doi: 10.1016/j.jpe.2015.05.028

[2] Ansari, Z. N., \& Kant, R. (2017), "A state-of-art literature review reflecting 15 years of focus on sustainable supply chain management", Journal of Cleaner Production, Vol. 142, pp. 2524-2543. https://doi. org/10.1016/j.jclepro.2016.11.023

[3] Baliga, R., Raut, R. D., \& Kamble, S. S. (2019), "Sustainable supply chain management practices and performance: An integrated perspective from a developing economy", Management of Environmental Quality: An International Journal, Vol. 31 No. 5, pp. 1147-1182. https://doi.org/10.1108/MEQ-04-2019-0079

[4] Christopher, M. (2011). Logistics and supply chain management (4th ed.). UK: Pearson.

[5] Beamon, B.M. and Chen, V.C.P. (2001), "Performance analysis of conjoined supply chains", International Journal of Production Research, Vol. 39, pp. 3195- 3218.

[6] Bozarth, C.C., Warsing, D.P., Flynn, B.B. and Flynn, E.J. (2009), "The impact of supply chain complexity on manufacturing plant performance", Journal of Operations Management, Vol. 27, pp. 78-93.

[7] Brandenburg, M., Govindan, K., Sarkis, J., and Seuring, S. (2014), "Quantitative models for sustainable supply chain management: Developments and directions", European Journal of Operational Research, Vol. 233 No. 2, pp. 299-312. doi: 10.1016/j.ejor.2013.09.032

[8] Brandenburg, M., and Rebs, T. (2015), "Sustainable supply chain management: a modeling perspective", Annals of Operations Research, Vol. 229 No. 1, pp. 213-252. doi:10.1007/s10479-015-1853-1

[9] Elgazzar, S., Tipi, N. and Jones, G. (2019). "Key characteristics for designing a supply chain performance measurement system", International Journal of Productivity and Performance, doi: 10.1108/ IJPPM-04-2018-0147. 
[10] Fahimnia, B., \& Jabbarzadeh, A. (2016). "Marrying supply chain sustainability and resilience: A match made in heaven. Transportation Research Part E: Logistics and Transportation Review, Vol. 91, pp. 306-324.

[11] Fahimnia, B., Sarkis, J., \& Talluri, S. (2019). "Editorial design and Management of Sustainable and Resilient Supply Chains. IEEE Transactions on Engineering Management, Vol. 66 No. 1, pp. 2-7. https://doi.org/10.1109/ TEM.2018.2870924

[12] Grant, D. B., Trauritrims, A., \& Wong, C. Y. (2017). "Sustainable logistics and supply chain managementprinciples and practices for sustainable operations and management". Great Britain: Kogan Page.

[13] Hearnshaw, E. J. S., and Wilson, M. M. J. (2013). "A complex network approach to supply chain network theory". International Journal of Operations \& Production Management, Vol. 33 No. 4, pp. 442-469. doi:10.1108/01443571311307343

[14] Jain, V. and Benyoucef, L. (2008), "Managing long supply chain networks: some emerging issues and challenges", Journal of Manufacturing Technology Management, Vol. 19, pp. 469-496.

[15] Ivanov, D., Dolgui, A and Sokolov, B. (2019), "The impact of digital technology and Industry 4.0 on the ripple effect and supply chain risk analytics". International Journal of Production Research, Vol. 57 No. 3, pp. 829846. doi:10.1080/00207543.2018.1488086

[16] Ivanov, D. and Dolgui, A. (2020), "Viability of intertwined supply networks: extending the supply chain resilience angles towards survivability. A position paper motivated by COVID-19 outbreak", International Journal of Production Research, Vol. 58 No. 10, pp. 2904-2915. doi:10.1080/00207543.2020.1750727

[17] Ivanov, D. (2020). "Viable supply chain model: integrating agility, resilience and sustainability perspectiveslessons from and thinking beyond the COVID-19 pandemic", Annals of Operations Research, 21. doi:10.1007/ s10479-020-03640-6

[18] Lepenioti, K., Bousdekis, A., Apostolou, D., \& Mentzas, G. (2020). "Prescriptive analytics: Literature review and research challenges". International Journal of Information Management, Vol. 50, pp. 57-70. doi:10.1016/j. ijinfomgt.2019.04.003.

[19] Mentzer, J.T., Dewitt, W., Keebler, J.S., Soonhoong, M., Nix, N.W., Smith, C.D. and Zacharia, Z.G. (2001), "Defining Supply Chain Management", Journal of Business Logistics, Vol. 22, pp. 1-25.

[20] Min, H. and Zhou, G. (2002), "Supply chain modeling: past, present and future", Computers \& Industrial Engineering, Vol. 43, pp. 231-249. doi: https://doi.org/10.1016/S0360-8352(02)00066-9.

[21] Negri, M., Cagno, E., Colicchia, C., \& Sarkis, J. (2021), "Integrating sustainability and resilience in the supply chain: A systematic literature review and a research agenda", Business Strategy and the Environment. doi: https://doi.org/10.1002/bse.2776.

[22] Pidd, M (2010), "Why modelling and model use matter", Journal of the Operational Research Society. Vol. 61, pp. 14-24.

[23] Tipi, Nicoleta (2021). "Supply Chain Analytics and Modelling: Quantitative Tools and Applications", Kogan Page, ISBN: 9780749498627, UK.

[24] Tipi, N.S. (2009). "Modelling performance measures for supply chain systems using discrete event simulation, Proceedings of the 14th International Symposium on Logistics", Istanbul, Turkey 5-8 July, 2009, p34.

[25] Wilding, R.D. (1998), "The supply chain complexity triangle: Uncertainty generation in the supply chain", International Journal of Physical Distribution \& Logistics Management, Vol. 28, pp. 599-616. 